Eur J Nucl Med Mol Imaging (2005) 32:623-624

DOI 10.1007/s00259-004-1751-2

Published online: 19 February 2005

(C) Springer-Verlag 2005

\section{Sweet nuclear medicine phantoms for scintigraphic sentinel lymph node detection: a cooking recipe}

\author{
Claudine Als 1,2, Peter Bräutigam¹, Siroos Mirzaei ${ }^{1}$ \\ 1 Service de Médecine Nucléaire, Clinique Ste Thérèse, 36, rue Ste \\ Zithe, 2763, Luxembourg, Grand-Duchy of Luxembourg \\ ${ }^{2}$ Institute of Clinical Chemistry, Inselspital, University of Bern, Bern, \\ Switzerland
}

\section{Dear Sir,}

Prior to clinical in vivo use of a gamma probe for sentinel lymph node detection in a cancer patient, it is advisable for practitioners to undergo training in the manipulation by means of a phantom. Especially in the case of full patient anaesthesia during surgery, e.g. for breast carcinoma, unnecessary prolongation of anaesthesia due to inadequate or untrained probe handling should be avoided. We have therefore designed a convenient anatomical phantom, based on a cooking recipe. Unusually for a nuclear medicine phantom, this one is sweet and coloured.

For the cooking recipe, take an amount of commercially available strawberry pudding powder appropriate for a volume of 21 and 24 gelatine leaves. Mix the pudding powder with six spoonfuls of sugar. Dissolve the powder in $100 \mathrm{ml}$ of cold milk. Briefly boil 21 of milk, remove from the heat and add the dissolved cold milkpudding mixture. Return to the boil and boil for $1 \mathrm{~min}$ while stirring gently. Dissolve the gelatine leaves in $100 \mathrm{ml}$ cold water and gently add to the liquid pudding. Fill up two receptacles: The first round bowl, about $5 \mathrm{~cm}$ in depth and $12 \mathrm{~cm}$ in diameter, is supposed to anatomically simulate the mammary gland. The second basin, of round or oval circumference and with a rather flat bottom, is supposed to simulate the thoracic wall. Place both receptacles in the refrigerator for at least $4 \mathrm{~h}$. Prepare four ${ }^{99 \mathrm{~m}} \mathrm{Tc}$ labelled 'hot spots': one 'injection site' plus three 'sentinel lymph nodes'. The activity of the 'injection site' is about 100 times higher than that of the 'sentinel nodes'. Our 'injection site' has an activity of $14.8 \mathrm{MBq}(0.4 \mathrm{mCi}=$ $100 \%)$, whereas the activities of the 'sentinel nodes' vary between $0.075 \mathrm{MBq}(0.002 \mathrm{mCi}=0.5 \%)$ and $0.150 \mathrm{MBq}$ $(0.004 \mathrm{mCi}=1 \%)$. Obtain organic capsules for pharmacological preparations from the pharmacist. Into each capsule, insert a tiny cotton swab labelled with ${ }^{99 \mathrm{~m}} \mathrm{Tc}$. As a humid environment such as a pudding dissolves the capsules, secure them temporarily by wrapping around a small amount of Scotch tape. The two cold puddings, now solidified, are still left in their receptacles. Insert the "injection site' capsule deeply into the breast model. Insert the 'sentinel node' capsules into the periphery of the thoracic wall or the breast model. Tip the thoracic wall model from the basin onto a plate and then carefully tip out the breast model on top of it. The hot spots will now be well hidden in the depths of the phantom (Fig. 1). Your humanoid phan- tom is now ready. It is of a firm consistency and looks quite lifelike.

Thereafter, handling of the probe may be initiated. Training may be provided in positioning, duration of acquisition, speed of movement and distance of the probe from the phantom, as well as in technical details concerning nuclide energy, threshold-related sensitivity, and the meaning of acoustic and visual signals. Localising the 'sentinel node' with the probe actually works (Fig. 1)! Due to dissolution of the capsule and hence dispersion of the 'hot spot', the spatial resolution of the 'sentinel node' detection is somewhat reduced after $30-60 \mathrm{~min}$. This is why radiolabelling and tipping out of the phantom should ideally be performed just prior to probe testing. Nevertheless, the phantom may be used for testing for up to $24 \mathrm{~h}$.

Standard discoid phantoms are routinely provided by manufacturers for evaluation of new gamma probes [1]. Humanoid phantoms of the female thorax or of the female mammary gland have been previously described in the management of sentinel node detection [2]. This is the first description of a disposable phantom based on a cooking recipe for use in scintigraphic sentinel node detection. Our surgical, gynaecological and dermatological colleagues tested the value of the phantom as an introduction to the technique, and thereafter felt confident in their ability to perform sentinel node detection in patients. As a consequence of the training, they were able to rapidly and accurately localise the radioactive sentinel node intraoperatively. The oft-cited intraoperative learning curve of the clinician might be shortened by use of our phantom, to the benefit of cancer patients. In addition, we felt that interdisciplinary collaboration was strengthened by the training. We therefore recommend this easily reproducible procedure to newcomers.

Finally, we are pleased to append some further comments: (1) We successfully repeated the probe test using a chocolate pudding phantom. (2) A probe test using a gelatine-only pudding was a failure, as insertion and hiding of the 'sentinel node' were impossible. (3) The large cheese cake from the baker's store, initially ordered with a view to radiolabelling and serving as a phantom, was instead eaten with pleasure. Bon appetit!

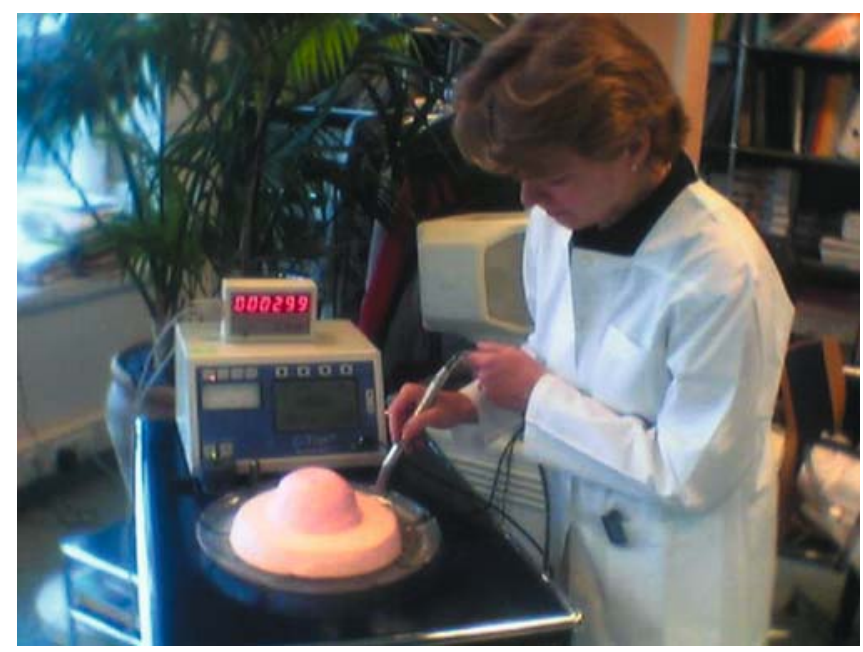

Fig. 1. Tracking the radioactive 'sentinel node' within the humanoid phantom with the gamma probe 
Claudine Als (-)

Service de Médecine Nucléaire, Clinique Ste Thérèse, 36, rue Ste Zithe, 2763, Luxembourg, Grand-Duchy of Luxembourg e-mail: claudine.als@insel.ch

Tel.: +352-49776-4986, Fax: +352-49776-5972

\section{References}

1. Pitre S, Menard L, Ricard M, Solal M, Garbay JR, Charon Y. A hand-held imaging probe for radio-guided surgery: physical performance and preliminary clinical experience. Eur J Nucl Med Mol Imaging 2003;30:339-43

2. Law M, Cheng KC, Wu PM, Ho WY, Chow LW. Patient effective dose from sentinel lymph node lymphoscintigraphy in breast cancer: a study using a female humanoid phantom and thermoluminescent dosemeters. Br J Radiol 2003;76:818-23. Comment in: $\mathrm{Br}$ J Radiol 2004;77:709 